\title{
ANALISIS VARIASI JUMLAH SUDU 6, 8 DAN 10 BUAH PADA VERTICAL AXIS WIND TURBINE JENIS STRAIGHT BLADE
}

\author{
${ }^{(1)}$ Gusti Rusydi Furqon Syahrillah, ${ }^{(2)}$ Yassyir Maulana \\ (1)Program Studi Teknik Mesin Universitas Islam Kalimantan MAAB \\ (2) Program Studi Teknik Industri Universitas Islam Kalimantan MAAB \\ Jl. Adhyaksa No.2 Kayutangi Banjarmasin \\ Email : rani rusdi@yahoo.com, yasir.industri@gmail.com
}

\begin{abstract}
Abstrak
Vertikal Axis Wind Turbine (VAWT) merupakan salah satu jenis turbin angin yang dapat digunakan pada kecepatan angin yang rendah dan dapat diletakkan pada tempat yang rendah. VAWT memiliki banyak jenis terutama dari jumlah sudu dan bentuk sudunya. Pada penelitian ini jenis sudu yang digunakan adalah jenis sudu datar (straight blade) dikarenakan pembuatan untuk jenis sudu mudah dan tidak membutuhkan pembiayaan yang mahal. Penelitian ini dilakukan untuk mengetahui jumlah sudu pada Vertikal Axis Wind Turbine (VAWT) yang paling optimal antara sudu 6, 8 dan 10 buah untuk menghasilkan daya poros turbin serta efisiensi yang terbaik. Metode penelitian yang digunakan adalah metode eksperimen, di mana dilakukan pengujian pada masing-masing VAWT dengan variasi jumlah sudu. Hasil dari penelitian menyatakan bahwa daya poros turbin yang paling tinggi dihasilkan oleh VAWT dengan Jumlah blade 6 Buah dengan nilai sebesar 16,1 Watt dan efisiensi turbin yang paling tinggi dihasilkan oleh VAWT jumlah blade 6 buah dengan nilai sebesar 48,3\%.
\end{abstract}

Kata Kunci : VAWT, Energi Terbarukan, Straight Blade

\begin{abstract}
Vertical axis wind turbine ( vawt) is one of a kind of wind turbines that can be used in wind speeds are low and can be laid on a low place.VAWT having many kinds especially of the number of blade and the shape of blade. In this research used kind of straight blade, because easy to making and not need expensive price. This report is written on the number of blade in vertical axis wind turbin (VAWT) most optimal between 6, 8 and 10 blade to produce the best power of turbine shaft and best turbine efficiency. Research methods that were used is the experimental methods, where do the tests at each VAWT which have variations of the quantity of blade. The results of the experiment are the highest produced power of turbine shaft that by VAWT to the total number of blade 6 with value about 16.1 Watts and the highest efficiency of a turbine that by VAWT 6 blade with value about 48,3 $\%$.
\end{abstract}

Keywords : VAWT, Reneweble Energy, Straight Blade 


\section{PENDAHULUAN}

Turbin angin adalah kincir angin yang digunakan untuk membangkitkan tenaga listrik. Turbin angin menghasilkan energi kinetik. Turbin angin ini pada awalnya dibuat untuk mengakomodasi kebutuhan para petani dalam melakukan penggilingan padi, keperluan irigasi, dll.

Turbin angin terdahulu banyak dibangun di Denmark, Belanda, dan negara-negara Eropa lainnya dan lebih dikenal dengan sebutan Windmill. Kini turbin angin lebih banyak digunakan untuk mengakomodasi kebutuhan listrik masyarakat, dengan menggunakan prinsip konversi energi dan menggunakan sumber daya alam yang dapat diperbaharui yaitu angin.

Untuk turbin angin skala kecil, jenis vertical axis wind turbine(VAWT) sangatlah cocok digunakan di daerah perkotaan karena karakteristik VAWT yang dapat bergerak tanpa tergantung arah angin, hal ini sesuai dengan karakteristik angin perkotaan. Selain itu, VAWT dapat bergerak dan menghasilkan energi listrik pada kondisi kecepatan angin yang rendah.

VAWT merupakan turbin angin sumbu tegak yang gerakan poros dan rotor sejajar dengan arah angin, sehingga rotor dapat berputar pada semua arah angin. VAWT juga mempunyai beberapa kelebihan dan kekurangan. Kelebihannya, yaitu memiliki torsi tinggi sehingga dapat berputar pada kecepatan angin rendah, generator dapat ditempatkan di bagian bawah turbin sehingga mempermudah perawatan dan kerja turbin tidak dipengaruhi arah angin. Kekurangannya yaitu kecepatan angin di bagian bawah sangat rendah sehingga apabila tidak memakai tower akan menghasilkan putaran yang rendah, dan efisiensi lebih rendah dibandingkan HAWT.

Tujuan dari penelitian ini adalah untuk mengetahui daya poros turbin serta efisiensi turbin yang terbaik di atara variasi jumlah sudu 6, 8 dan 10 buah.

\section{METODE PENELITIAN}

Tempat untuk penelitian proses pengujian VAWT dilakukan di Laboraturium Fakultas Teknik Univeritas Islam Kalimantan (Uniska) Muhammad Arsyad Al Banjari Banjarmasin.

Metode yang digunakan pada penelitian ini adalah metode uji eksperimen, di mana hasil penelitian akan diketahui setelah dilakukan pengujian pada VAWT. Tahapantahapan pada penelitian ini dapat seperti berikut :

1. Perancangan Turbin Angin Bersumbu Vertikal (VAWT) dengan menggunkan Software Autodesk Inventor.

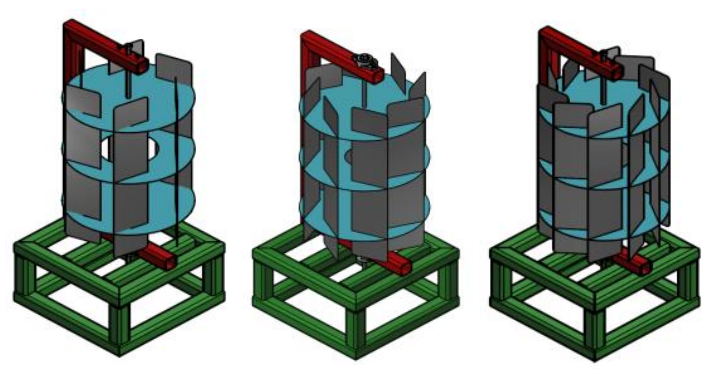

Gambar 1. Desain VAWT 3D Dimensi

2. Pembuatan Turbin Angin Bersumbu Vertikal (VAWT).

3. Proses pengujian VAWT dengan menggunakan Wind Tunnel.

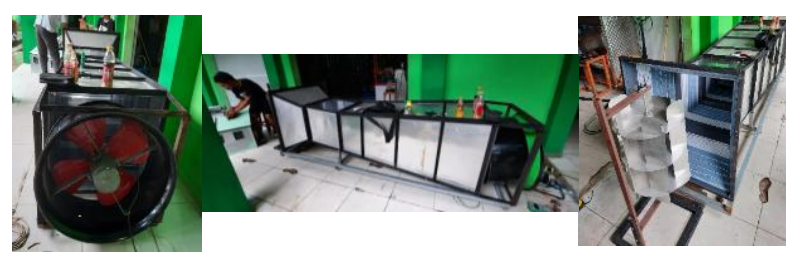

Gambar 2. Wind Tunnel

4. Pengambilan data berupa kecepatan angin dan kecepatan putaran VAWT dengan menggunakan anemometer dan tachometer.

5. Pengolahan data dan analisis data 
6. Perhitungan daya angin, tip speed ratio, efisiensi turbin angin dan daya poros

\section{HASIL DAN PEMBAHASAN}

Data yang diperoleh dari pengujian menggunakan Wind Tunnel dengan jumlah blade 6,8 dan 10 meliputi data kecepatan angin $(\mathrm{m} / \mathrm{s})$ dan kecepatan putaran poros vertical axis wind turbine (rpm). Pengukuran kecepatan angin $(\mathrm{m} / \mathrm{s})$ pada kipas angin menggunakan anemometer sedangkan untuk mengukur kecepatan putaran (rpm) digunakan tachometer dan pengambilan data dilakukan sebanyak 9 kali untuk masingmasing pengukuran kecepatan angin dan kecepatan putaran.

Tabel 1. Data Hasil Pengambilan Data

\begin{tabular}{|c|c|c|}
\hline $\begin{array}{l}\text { Jumlah } \\
\text { Blade }\end{array}$ & $\begin{array}{c}\text { Kecepatan Angin } \\
v(\mathrm{~m} / \mathrm{s})\end{array}$ & $\begin{array}{c}\text { Kecepatan Putaran } \\
n(\mathrm{Rpm})\end{array}$ \\
\hline \multirow{9}{*}{6} & 4,7 & 219 \\
\hline & 4,8 & 220 \\
\hline & 5,2 & 222 \\
\hline & 5,4 & 225 \\
\hline & 5,5 & 228 \\
\hline & 5,8 & 230 \\
\hline & 6 & 232 \\
\hline & 6,2 & 236 \\
\hline & 6,5 & 238 \\
\hline \multirow{9}{*}{8} & 4,7 & 209 \\
\hline & 4,8 & 214 \\
\hline & 5,2 & 217 \\
\hline & 5,4 & 220 \\
\hline & 5,5 & 222 \\
\hline & 5,8 & 225 \\
\hline & 6 & 228 \\
\hline & 6,2 & 231 \\
\hline & 6,5 & 232 \\
\hline \multirow{9}{*}{10} & 4,7 & 198 \\
\hline & 4,8 & 202 \\
\hline & 5,2 & 207 \\
\hline & 5,4 & 210 \\
\hline & 5,5 & 214 \\
\hline & 5,8 & 217 \\
\hline & 6 & 221 \\
\hline & 6,2 & 224 \\
\hline & 6,5 & 226 \\
\hline
\end{tabular}

\section{Daya Angin}

Untuk menghitung daya angin, persamaan yang digunakan adalah persamaan berikut yaitu :

$$
\begin{aligned}
& P_{\text {Angin }}=0,5 \times \rho \times A \times v^{3} \\
& P_{t}=T \times \omega \\
& P_{t}=0,65 \times 22,9=14,8 \mathrm{Watt}
\end{aligned}
$$

$$
\begin{aligned}
& P_{\text {Angin }}=0,5 \times 1,184 \times 0,5 \times 4,7^{3} \\
& P_{\text {Angin }}=30,7 \mathrm{Watt}
\end{aligned}
$$

\section{Tip Speed Ratio (TSR)}

Sebelum menghitung TSR, maka harus dihitung kecepatan sudut $(\omega)$ terlebih dahulu

$$
\begin{aligned}
& \omega=\frac{n \times \pi}{30} \\
& \omega=\frac{219 \times 3,14}{30} \\
& \omega=22,9 \mathrm{rad} / \mathrm{s}
\end{aligned}
$$

Untuk nilai $r_{\text {Kincir }}$ (jari-jari kincir) diketahui 0,165 Sehingga nilai TSR untuk kecepatan putaran 219 rpm pada kecepatan angin $4,8 \mathrm{~m} / \mathrm{s}$ adalah sebagai berikut:

$$
\begin{aligned}
& T S R=\frac{\omega \times r_{\text {Kincir }}}{v} \\
& T S R=\frac{22,9 \times\left(\frac{0,33}{2}\right)}{4,7} \\
& T S R=0,80
\end{aligned}
$$

\section{Torsi}

Torsi adalah gaya yang bekerja mengelilingi sebuah titik yang dalam penerapannya digunakan untuk memutar benda. Torsi dapat ditulis dengan persamaan sebagai berikut, dengan asumsi massa turbin sebesar $0,4 \mathrm{Kg}$ :

$$
\begin{aligned}
& T=F \times r_{\text {kincir }} \\
& T=(m . g) \times r_{\text {kincir }} \\
& T=(0,4 \times 9,81) \times 0,165 \\
& T=0,65 N . m
\end{aligned}
$$

\section{Daya Poros Turbin}

Daya poros turbin merupakan daya dari angin yang memberikan beban kepada turbin sehingga berputar. rumus yang digunakan untuk menghitung daya poros turbin adalah. 
Efisiensi Turbin

Efisiensi VAWT adalah perbandingan antara daya yang diserap turbin angin terhadap daya angin yang tersedia. Berikut perhitungan efisiensi turbin.

$$
\begin{aligned}
\eta_{w t} & =\frac{P_{t}}{P_{\text {in }}} \times 100 \% \\
\eta_{w t} & =\frac{14,8}{30,7} \times 100 \%=48,3 \%
\end{aligned}
$$

\begin{tabular}{|c|c|c|c|c|c|c|c|}
\hline $\begin{array}{c}\text { Jumlah } \\
\text { Blade }\end{array}$ & $\begin{array}{c}\text { Kecepatan } \\
\text { Angin } \\
v(\mathrm{~m} / \mathrm{s})\end{array}$ & $\begin{array}{c}\text { Kecepatan } \\
\text { Putaran } \\
n(\mathrm{Rpm})\end{array}$ & $\begin{array}{c}\text { Daya } \\
\text { Angin } \\
P_{\text {Angin }} \\
\text { (Watt) }\end{array}$ & $\begin{array}{l}\text { Kecepatan } \\
\text { Sudut } \\
\omega(\mathrm{rad} / \mathrm{s})\end{array}$ & TSR & $\begin{array}{l}\text { Daya } \\
\text { Turbin } \\
\text { (Watt) }\end{array}$ & $\begin{array}{c}\text { Efisiensi } \\
\text { Turbin } \\
(\%)\end{array}$ \\
\hline \multirow{9}{*}{6} & 4,7 & 219 & 30,7 & 22,9 & 0,80 & 14,8 & 48,3 \\
\hline & 4,8 & 220 & 32,7 & 23,0 & 0,79 & 14,9 & 45,5 \\
\hline & 5,2 & 222 & 41,6 & 23,2 & 0,74 & 15,0 & 36,1 \\
\hline & 5,4 & 225 & 46,6 & 23,6 & 0,72 & 15,2 & 32,7 \\
\hline & 5,5 & 228 & 49,2 & 23,9 & 0,72 & 15,5 & 31,4 \\
\hline & 5,8 & 230 & 57,8 & 24,1 & 0,68 & 15,6 & 27,0 \\
\hline & 6 & 232 & 63,9 & 24,3 & 0,67 & 15,7 & 24,6 \\
\hline & 6,2 & 236 & 70,5 & 24,7 & 0,66 & 16,0 & 22,7 \\
\hline & 6,5 & 238 & 81,3 & 24,9 & 0,63 & 16,1 & 19,8 \\
\hline \multirow{9}{*}{8} & 4,7 & 209 & 30,7 & 21,9 & 0,77 & 14,2 & 46,1 \\
\hline & 4,8 & 214 & 32,7 & 22,4 & 0,77 & 14,5 & 44,3 \\
\hline & 5,2 & 217 & 41,6 & 22,7 & 0,72 & 14,7 & 35,3 \\
\hline & 5,4 & 220 & 46,6 & 23,0 & 0,70 & 14,9 & 32,0 \\
\hline & 5,5 & 222 & 49,2 & 23,2 & 0,70 & 15,0 & 30,5 \\
\hline & 5,8 & 225 & 57,8 & 23,6 & 0,67 & 15,2 & 26,4 \\
\hline & 6 & 228 & 63,9 & 23,9 & 0,66 & 15,5 & 24,2 \\
\hline & 6,2 & 231 & 70,5 & 24,2 & 0,64 & 15,7 & 22,2 \\
\hline & 6,5 & 232 & 81,3 & 24,3 & 0,62 & 15,7 & 19,3 \\
\hline \multirow{9}{*}{10} & 4,7 & 198 & 30,7 & 20,7 & 0,73 & 13,4 & 43,7 \\
\hline & 4,8 & 202 & 32,7 & 21,1 & 0,73 & 13,7 & 41,8 \\
\hline & 5,2 & 207 & 41,6 & 21,7 & 0,69 & 14,0 & 33,7 \\
\hline & 5,4 & 210 & 46,6 & 22,0 & 0,67 & 14,2 & 30,5 \\
\hline & 5,5 & 214 & 49,2 & 22,4 & 0,67 & 14,5 & 29,4 \\
\hline & 5,8 & 217 & 57,8 & 22,7 & 0,65 & 14,7 & 25,5 \\
\hline & 6 & 221 & 63,9 & 23,1 & 0,64 & 15,0 & 23,4 \\
\hline & 6,2 & 224 & 70,5 & 23,4 & 0,62 & 15,2 & 21,5 \\
\hline & 6,5 & 226 & 81,3 & 23,7 & 0,60 & 15,3 & 18,8 \\
\hline
\end{tabular}

Tabel 1. Hasil Rekapitulasi Perhitungan Efisiensi Turbin 


\section{Grafik Daya Poros Turbin VAWT Jumlah Blade 6, 8 dan 10 Buah}

Data-data dari hasil perhitungan diolah kembali dalam bentuk grafik untuk mengetahui Efisiensi Turbin dan Daya Poros Turbin dari VAWT dengan jumlah Blade 6, 8 dan 10 buah.

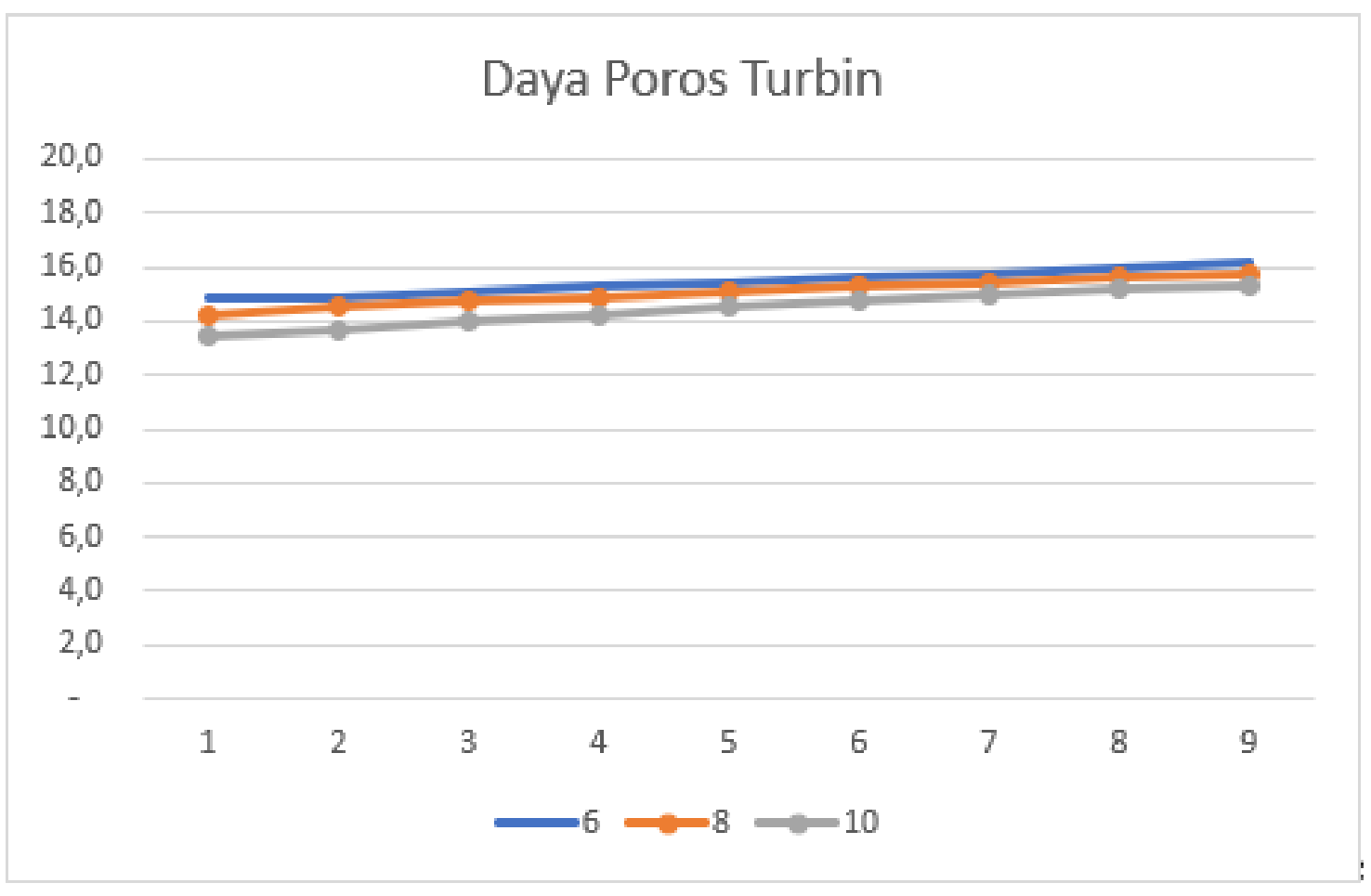

Gambar 3. Grafik Efisiensi Turbin

Dari gambar grafik di atas dapat dilihat bahwa daya poros turbin akan meningkat seiring dengan meningkatnya kecepatan angin. VAWT dengan jumlah blade 6 buah menghasilkan daya turbin yang paling tinggi dibandingkan dengan VAWT dengan jumlah blade 8 dan 10 buah dengan nilai 16,1 Watt. Dari grafik di atas dapat dilihat juga ada peningkatan daya seiring kecepatan putaran. Dilihat dari daya turbin yang dihasilkan bahwa perbedaan jumlah sudu cukup mempengaruhi walaupun tidak begitu signifikan perbedaannya.

\section{Grafik Efisiensi VAWT Jumlah Blade 6, 8 dan 10}

Dari gambar grafik di bawah dapat dilihat bahwa efisiensi turbin tertinggi diperoleh VAWT dengan jumlah blade 6 buah, tetapi ketika kecepatan angin bertambah efisiensi dari tubin tersebut cenderung menurun. Sedangkan pada VAWT dengan jumlah blade 8 , dan 10 buah, memiliki efisiensi yang lebih kecil dibanding dengan jumlah blade 6 pada kecepatan rendah dengan nilai 48,3\%. Efisiensi turbin berdasarkan perhitungan mengalami penurunan ketika nilai TSR mengalami penurunan. Nilai TSR berbanding terbalik dengan kecepatan angin yang berarti jika kecepatan angin meningkat maka nilai tip speed ratio (TSR) akan menjadi turun yang berarti efisiensi juga ikut turun Ketika kecepatan angin meningkat.

Hal ini dikarenakan angin tidak bisa menerobos melalui celah pada turbin, sehingga kecepatan tinggi kecepatan angin, maka losses yang terjadi juga semakin besar yang menyebabkan efisiensi yang dihasilkan juga semakin menurun. 


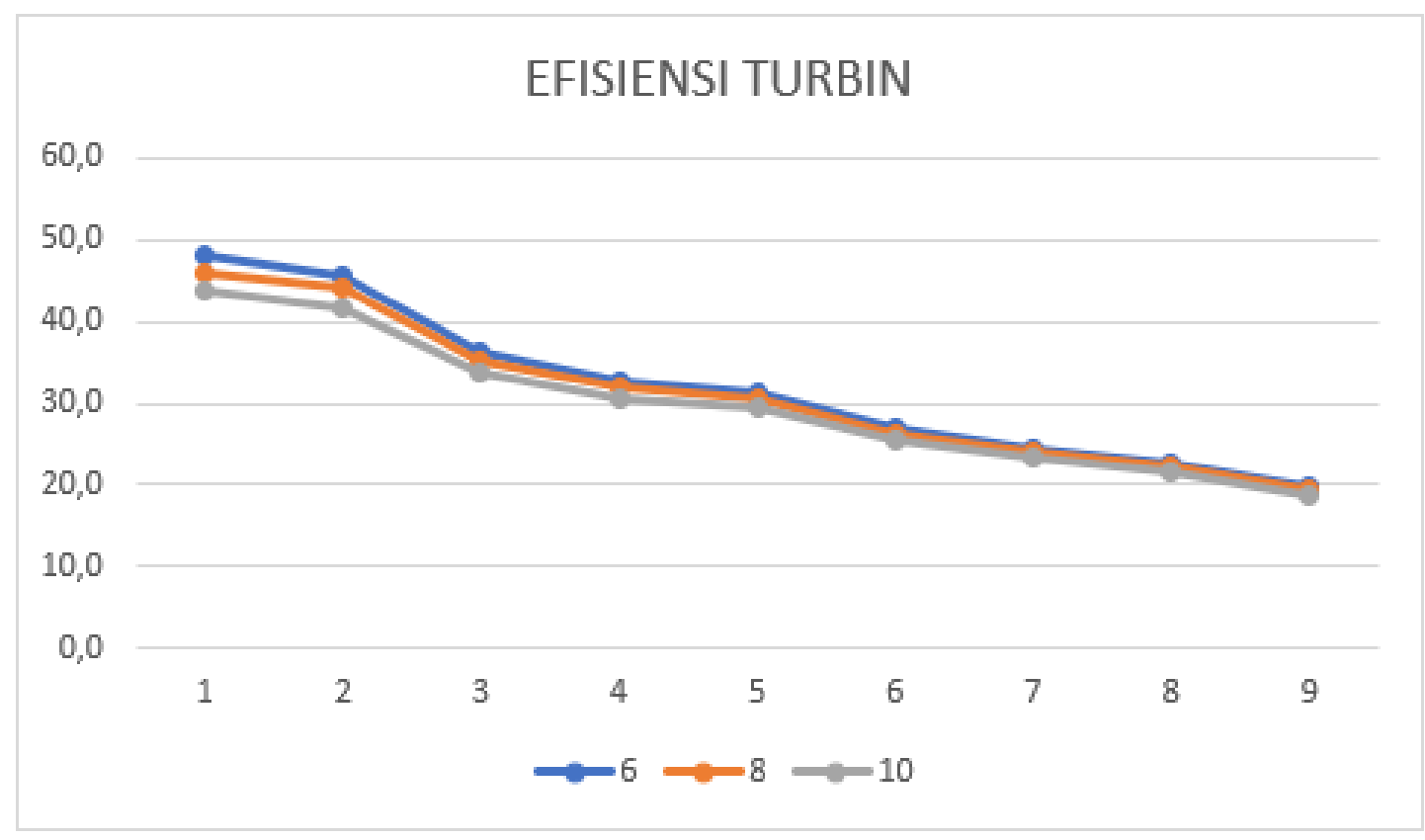

Gambar 4. Grafik Efisiensi Turbin

\section{KESIMPULAN}

Dari hasil penelitian Vertical Axis Wind Turbine jenis Straight Blade dengan jumlah blade 6,8 dan 10 buah dapat disimpulkan sebagai berikut :

1. Daya Poros Turbin tertinggi diperoleh VAWT dengan jumlah Blade 6 buah dengan nilai sebesar 16,1 watt pada kecepatan putaran sebesar 238 Rpm. Sedangkan untuk jumlah blade 8 dan 10, daya poros turbin tertinggi sebesar 15,7 watt dan 15,3 watt pada kecepatan putaran $232 \mathrm{Rpm}$ dan $226 \mathrm{Rpm}$

2. Efisiensi Turbin yang paling tinggi diperoleh VAWT dengan jumlah blade 6 buah dengan nilai sebesar $48,3 \%$. Sedangkan untuk jumlah blade 8 dan 10, nilai efisiensinya sebesar 46,1\% dab 43,7\%.

\section{REFERENSI}

[1] Aryanto, F., Mara, M., \& Nuarsa, M. (2013).

PENGARUH

KECEPATAN ANGIN DAN

VARIASI JUMLAH SUDU

TERHADAP UNJUK KERJA TURBIN ANGIN POROS
HORIZONTAL. Dinamika Teknik Mesin, 3(1). https://doi.org/10.29303/d.v3i1.88

[2] Faadhil, M., \& Anis, S. (2018). PENGARUH SUDUT SERANG TERHADAP KINERJA TURBIN ANGIN HELIKS GORLOV DENGAN PENAMBAHAN CURVEPLATE. Sainteknol, 16(1), 16.

[3] Iswahyudi, \& Siregar, I. H. (2018). STUDI PENGEMBANGAN PENGARAH ANGIN SEBAGAI UPAYA PENINGKATAN KINERJA TURBIN ANGIN DUA TINGKAT DARRIEUS TYPE H. Jurnal Pendidikan Teknik Mesin (JPTM), 6(3), 65-71.

[4] Junaidin, B. (2017). PERANCANGAN VERTICAL AXIS WIND TURBINE (VAWT) SKALA KECIL. Jurnal Ilmiah Bidang Teknologi, ANGKASA, IX(2), 10.

[5] Mahendra, B., Soenoko, R., \& Sutikno, D. (2013). PENGARUH JUMLAH SUDU TERHADAP UNJUK KERJA TURBIN ANGIN SAVONIUS TYPE L [Skripsi, Universitas Brawijaya]. 
https://www.academia.edu/9444842 /PENGARUH_JUMLAH_SUDU TERHADAP_UNJUK_KERJA_T URBIN_ANGIN_SAVONIUS_TY PE_L

[6] Maulana, Y., \& Sidiq, A. (2018). Perancangan Vertical Axis Wind Turbine (VAWT) jenis Straight Blade. Journal of Industrial Engineering and Operation Management, $1(2)$. https://ojs.uniskabjm.ac.id/index.php/jieom

[7] Nakhoda, Y. I., \& Saleh, C. (2015). Rancang Bangun Kincir Angin Sumbu Vertikal Pembangkit Tenaga Listrik Portabel. Seminar Nasional Sains dan Teknologi Terapan III, 10.

[8] Napitupulu, F. H., \& Mauritz, F. (2013). UJI EKSPERIMENTAL DAN ANALISIS PENGARUH VARIASI KECEPATAN DAN JUMLAH SUDU TERHADAP DAYA DAN PUTARAN TURBIN ANGIN VERTIKAL AXIS SAVONIUS DENGAN MENGGUNAKAN SUDU PENGARAH. Jurnal Dinamis, 2(12), 49-59.

[9] Permadi, M. F. W., \& Siregar, I. H. (2018). UJI EKSPERIMENTAL TURBIN ANGIN SUMBU VERTIKAL JENIS CROSS FLOW DENGAN VARIASI JUMLAH BLADE. JTM, 06(1), 15-31.

[10] Saputra, D. A. (2017). UNJUK KERJA KINCIR ANGIN MULTIBLADEDENGAN VARIASI
KONFIGURASI MAGNET [Skripsi]. Universitas Sanata Dharma Yogyakarta.

[11] Suprapto, M. (2016). ANALISIS TURBIN ANGIN SUMBU VERTIKAL DENGAN 4, 6 DAN 8. Jurnal Teknik Mesin UNISKA, 02(01), 6 .

[12] Tonglolangi, Y. Y. (2014). ANALISIS KINERJA KINCIR ANGIN SEDERHANA DENGAN DUA SUDU POROS HORIZONTAL. Journal Dynamic Saint, 1(2), Article 2. http://journals.ukitoraja.ac.id/index. php/dynamicsaint/article/view/129

[13] Vaishali V, A., Patil, S. A., \& Thakur, A. G. (2014). Optimization of Savinius Rotor for Wind Turbine. International Journal of Advances in Engineering \& Technology (IJAET), 7(4), 1294-1299.

[14] Vanessa, M. C. (2016). LAPORAN PENELITIAN RISET MINI TENTANG TURBIN ANGIN MODEL SAVONIUS DAN DARRIEUS [Laporan Penelitian]. Universitas Surya.

[15] Wiharno, F. B. (2016). UNJUK KERJA MODEL KINCIR ANGIN PROPELER TIGA SUDUDATAR DARI BAHAN TRIPLEK DENGAN SUDUT PATAHAN $10^{\circ} \mathrm{LEBAR}$ 10,5 CM DENGAN EMPAT VARIASI PERMUKAAN SUDU [Skripsi]. Universitas Sanata Dharma Yogyakarta. 